\title{
Evidence of light-induced phenotypic plasticity in zoanthids: editorial comment on the feature article by Wei et al.
}

\author{
Ross Hill
}

Received: 15 March 2013/ Accepted: 18 March 2013/Published online: 27 March 2013

(C) Springer-Verlag Berlin Heidelberg 2013

Phenotypic plasticity refers to the morphological variation of a single genotype across different environments (Kelly et al. 2012). The adaptive advantage of phenotypic plasticity includes the capacity for adjusting to variable environments across multiple habitats and over time as environments experience change. This ability has been documented in a range of benthic marine organisms, including corals (Hoeksema 2012). Like corals and anemones, zoanthids are anthozoans which often harbour symbiotic dinoflagellates (from the genus Symbiodinium). However, zoanthids have received considerably less attention compared to their cnidarian counterparts, with respect to their ecology. It is known that zoanthids exhibit high intraspecific morphological variability (Reimer et al. 2004), but it has been unclear whether this is due to polymorphism, phenotypic plasticity, or a combination of both.

The study by Wei et al. (2013) presents the first evidence for phenotypic plasticity in zoanthids. Colonies of Zoanthus sansibaricus and Palythoa tuberculosa all displayed lightinduced changes in morphology. Based on reaction norms, principal components analysis, analysis of variance, and canonical discriminant analysis, the authors demonstrate morphological differences between shading treatments, but also between local populations and a population $\times$ treatment effect. Polyps of shaded colonies were generally larger and taller than those of unshaded colonies.

Communicated by U. Sommer.

R. Hill ( $\bowtie)$

Centre for Marine Bio-Innovation and Sydney Institute

of Marine Science, School of Biological, Earth and

Environmental Sciences, The University of New South Wales,

Sydney, NSW 2052, Australia

e-mail: Ross.Hill@unsw.edu.au
Population $\times$ environment interactions show that populations of both species varied in the magnitude and direction of their morphologic responses to shading, suggesting some degree of acclimatization or local adaptation to natal reefs. Importantly, the authors have provided evidence that environmentally mediated changes can contribute to the morphological variation often described in zoanthids (Burnett et al. 1997). These morphologically plastic attributes may enable them to withstand temporal changes in their environment. In addition, given phenotypic plasticity is often associated with a generalist life strategy, these species of zoanthids may survive in spatially variable habitats (van Tienderen 1991). Therefore, this study not only clarifies the effect of illumination in zoanthids but also gives a more general insight on morphology in anthozoans that harbour symbiotic algae.

\section{References}

Burnett WJ, Benzie JAH, Beardmore JA, Ryland JS (1997) Zoanthids (Anthozoa, Hexacorallia) from the Great Barrier Reef and Torres Strait, Australia: systematics, evolution and a key to species. Coral Reefs 16:55-68

Hoeksema BW (2012) Extreme morphological plasticity enables a free mode of life in Favia gravida at Ascension Island (South Atlantic). Mar Biodiv 24:289-295

Kelly SA, Panhuis TM, Stoehr AM (2012) Phenotypic plasticity: molecular mechanisms and adaptive significance. Compr Physiol 2:1417-1439

Reimer JD, Ono S, Takishita K, Fujiwara Y, Tsukahara J (2004) Reconsidering Zoanthus spp. diversity: molecular evidence of conspecificity within four previously presumed species. Zool Sci 21:517-525

van Tienderen PH (1991) Evolution of generalists and specialist in spatially heterogeneous environments. Evolution 45:1317-1331

Wei ON, Reimer JD, Todd PA (2013) Morphologically plastic responses to shading in the zoanthids Zoanthus sansibaricus and Palythoa tuberculosa. Mar Biol. doi:10.1007/s00227-012-2158-4 